\title{
EVALUASI PELAKSANAAN PROGRAM UPAYA KESEHATAN JIWA DI PUSKESMAS SINDANG BARANG KOTA BOGOR PROVINSI JAWA BARAT TAHUN 2020
}

\section{Titik Prihartanti' ${ }^{1}$, Siti Khodijah Parinduri², Asri Masitha Arsyati ${ }^{3}$}

${ }^{1}$ Konsentrasi Manajemen Pelayanan Kesehatan Program (MPK), Program Studi Kesehatan Masyarakat Fakultas Ilmu KesehatanUniversitas Ibn Khaldun Bogor. Jl. K.H Sholeh Iskandar Raya Km. 2, Kedung Badak, Bogor 16161, Jawa Barat.Email : titikprihartanti45@gmail.com

2,3Program Studi Kesehatan Masyarakat Fakultas Ilmu KesehsatanUniversitas Ibn Khaldun Bogor. Jl. K.H Sholeh Iskandar Raya Km. 2, Kedung Badak, Bogor 16161, Jawa Barat.

\begin{abstract}
Abstrak
Riskesdas 2018, prevalensi rumah tangga yang memiliki anggota rumah tangga yang mengalami gangguan jiwa berat seperti skizofrenia/psikosis di Jawa Barat mencapai 5\% per mil. Jumlah Gangguan mental emosional secara nasional pada tahun 2013 mencapai 6,5\% meningkat menjadi 9,8\% pada tahun 2018, sedangkan skizofrenia pada tahun 2013 mencapai 3\% meningkat menjadi 7\% pada tahun 2018. Menurut data Puskesmas Sindang Barang jumlah kunjungan penderita gangguan jiwa pada tahun 2016 tercatat 184, pada tahun 2017 tercatat 204 kunjungan, pada tahun 2018 tercatat 445 kunjungan. Tujuan dari penelitian ini adalah untuk Mengetahui Evaluasi Pelaksanaan Program Kesehatan Jiwa di Puskesmas Sindang Barang. Jenis penelitian ini merupakan penelitian kualitatif yang bersifat deskriptif dengan desain studi kasus, instrument yang digunakan adalah wawancara mendalam, observasi dan telaah dokumen. Informan dalam penelitian ini sebanyak 12 orang. Variabel dalam penelitian ini terdiri dari variabel input,proses dan output. Hasil penelitian yang di dapat dari variabel input dalam program kesehatan jiwa untuk SDM masih belum merata dikarenakan wilayah yang cukup luas, dana bersumber dari dana BOK, sarana dan prasarana belum merata dikarenakan masih ada beberapa obat yang tidak tersedia. Dalam variabel proses masih ditemukan beberapa kendala. Dalam penyuluhan kurang tertariknya masyarakat dalam penyuluhan, sedangkan dalam sistem rujukan masih terjadinya beberapa kendala salah satunya izin dari pihak keluarga untuk melakukan rujukan. Kesimpulan penelitian ini adalah penatalaksanaan program kesehatan jiwa di puskesmas sindang barang sudah cukup baik, namum belum maksimal. meskipun angka deteksi dini sudah mencapai target maka sebaiknya pihak puskesmas lebih fokus terhadap penurunan angka jumlah kunjungan.
\end{abstract}

Kata kunci : Program Kesehatan Jiwa, Evaluasi Program, Kesehatan Jiwa.

\section{PENDAHULUAN}

Menurut UU Kesehatan Jiwa No. 18 tahun 2014 pasal 1 disebutkan kesehatan jiwa merupakan kondisi dimana seorang individu dapat berkembang secara fisik, mental, spiritual, dan sosial sehingga individu tersebut menyadari kemampuan sendiri, dapat mengatasi tekanan, dapat bekerja secara produktif, dan mampu memberikan kontribusi untuk komunitasnya. 
Menurut data World Health Organization (WHO), terdapat sekitar 35 juta orang terkena depresi, 60 juta orang terkena bipolar, 21 juta orang terkena skizofrenia, serta 47,5 juta terkena dimensia. Gangguan jiwa dapat disebabkan oleh berbagai faktor, pertama faktor biologis, seperti faktor keturunan, ketidak seimbangan zat di otak akibat cedera otak, penyakit pada otak dan penyalahgunaan narkoba, kecelakaan di kepala, dan sebagainya, kedua faktor psikologis seperti tidak bisa menyesuaikan diri dengan perubahan yang terjadi di lingkungan, kepribadian kurang matang, trauma psikologis masa lalu, konflik batin, dan keinginan yang tidak tercapai sehingga menimbulkan frustrasi, faktor ketiga yaitu faktor sosial seperti masalah hubungan dalam keluarga, konflik dengan orang lain, masalah ekonomi, pekerjaan dan tekanan dari lingkungan sekitar, ada masalah yang tidak dapat di atasi, dukungan yang kurang dari keluarga dan lingkungan, hingga keadaan trauma pasca bencana. Gangguan jiwa yang sering di temui antara lain gangguan cemas, gangguan depresi dan gangguan jiwa berat (psikosis). Dampak dari gangguan jiwa akan menimbulkan disabilitas serta dapat menurunkan produktivitas masyarakat dan beban biaya cukup besar. (Profil Kesehatan, 2018).

Data Riskesdas 2018, prevalensi rumah tangga yang memiliki anggota rumah tangga yang mengalami gangguan jiwa berat seperti skizofrenia/psikosis di Jawa Barat mencapai 5\% per mil, dibanding angka Nasional sebesar 7\% per mil. Pada tahun 2018 Prevalensi gangguan mental emosional pada penduduk usia $>15$ tahun di Provinsi Jawa Barat mencapai 11\%. Pada tahun 2013 Prevalensi gangguan mental emosional pada penduduk usia $>15$ tahun di Provinsi Jawa Barat sebesar 9\% (Riskesdas, 2018).

Tabel 1.1 Jumlah Kunjungan ODGJ Puskesmas Sindang Barang

\begin{tabular}{|r|c|c|c|c|}
\hline \multicolumn{1}{|c|}{ No } & Tahun & $\begin{array}{c}\text { Jumlah } \\
\text { penduduk }\end{array}$ & $\begin{array}{c}\text { Jumlah } \\
\text { kunjungan }\end{array}$ & $\%$ \\
\hline 1. & 2015 & 51,854 & 7,356 & 0.1418 \\
\hline 2. & 2016 & 51,059 & 184 & 0,0036 \\
\hline 3. & 2017 & 52,996 & 204 & 0,0038 \\
\hline 4. & 2018 & 69,211 & 445 & 0,00075 \\
\hline
\end{tabular}

Menurut data Puskesmas Sindang Barang jumlah kunjungan penderita gangguan jiwa pada tahun 2016 tercatat 184, pada tahun 2017 tercatat 204 kunjungan, pada tahun 2018 tercatat 445 kunjungan.

\section{METODE PENELITIAN}

Penelitian ini dilakukan oleh mahasiswa Program Studi Kesehatan Masyarakat Fakultas Ilmu Kesehatan Universitas Ibn Khaldun Bogor yang bertujuan untuk mengetahui evaluasi Pelaksanaan Program Kesehatan Jiwa di Puskesmas Sindang Barang dengan Informan yang terdiri dari 5 keluarga pasien , 5 kader kesehatan jiwa, 1 programer kesehatan jiwa , 1 kepala program kesehatan jiwa. Penulis menggunakan metode kualitatif bersifat deskriptif yang diperoleh melalui wawancara mendalam, observasi, dan telaah dokumen. Peneliti memilih Puskesmas Sindang Barang karena memiliki Jumlah Kunjungan gangguan jiwa yang 
meningkat dari tahun 2016- 2018. Penelitian ini dilaksanakan terhitung sejak bulan Februari hingga November 2020.

\section{HASIL PENELITIAN}

\section{Input}

\section{a. Sumber Daya Manusia ( SDM )}

Hasil yang di dapat dari wawancara mendalam kepada petugas Puskesmas sindang barang bahwa sumber daya manusia yang terlibat dalam pelaksanaan program kesehatan jiwa adalah 7 orang yang berasal dari Puskesmas dan kader,dan mereka saling berkerjasama untuk mendukung program kesehatan jiwa di puskesmas sindang barang,tetapi untuk jumlah SDM ternyata masih kurang berikut kutipan wawancaranya :

"kalo untuk berdasarkan seluruh wilayah karna wilayah sindang barang itu kan luas ada 5 kelurahan untuk programmer jiwanya itu kan saya untuk perawatnya dann ada penanggung jawabnya dokter satu gitu jadi dengan jumlah penduduk yang sekian itu sekitar hampir 60rb jiwa sebenarnya kurang tapi memang kita kan harus memanfaatkan yang ada gitu tapipaling kita dibantu kader aja." I1

"Jumlahnya sejauh ini hanya saya dan bu yeni saja untuk dibilang cukup atau tidak tentu untuk memegang 5 wilayah masih kurang ya,karena kan tugas saya juga bukan hanya di keswa saja jadikalo untuk kecukupan si masih kurang ya. Tapi kita dibantu kader juga" I2

Partisipasi masyarakat dalam pelayanan masalah kesehatan jiwa amat penting. Salah satu sumber daya yang memiliki peran penting dalam membantu Puskesmas dalam menangani masalah kesehatan jiwa di masyarakat ialah kader, berikut kutipan wawancaranya :

"Kader sangat membantu sejauh ini sih tapi untuk lebih jelasnya bisa ditanya ke bu yeni ya teknis dilapangan seperti apa" I2

"eeeee untuk mengurangi ini efektif atau tidak saya sudah melatih kader kesehatan jiwa yang sebagai perpanjangan tangan saya untuk dilapangan jadi kalo misalnya ada permasalahan bagaimana minum obatnya itu semua itu tugas kader kesehatan jiwa,jadi misalnya nanti ada pasien yang datang untuk ngambil obat tinggal menghubungi kader kan kita ada grup wanya per grup wilayah. itu untuk mempermudah saya gitu jadi kader sangat membantu sih." I1

dalam rangka menguatkan kemampuan dalam mendeteksi dini gangguan jiwa maka Puskesmas dan dinas juga mengupayakan pelatihan kader serta programmer jiwa, seperti dikatakan oleh informan:

" ee ginii, kalo kaya saya dilatih itu langsung sama ui ya saya di Jakarta itu waktu itu sekitar 14 hari ya 10 hari trus 4 hari kita ada dilapangan kurang lebih ada dua mingguan trus kemudian dari marzoeki Mahdi kan kita sudah ada kerjasama ACT assertive community treatment nah kita juga dilatih sama mereka nah terus dari dinas kesehatan baru baru ini juga megadakan pelatihan" I1

" kalo saya pribadi sih belum pernah ikut ya untuk pelatihan pelatihan itu karna masih terbilang baru kan saya memegang program kesehatan jiwa ini.” I2 


\section{b. Anggaran}

Dana yang diterima puskesmas untuk menjalankan program Upaya Kesehatan Jiwa berasal dari BOK (Biaya Operasional Kesehatan) dari pusat. Dana yang sudah diterima oleh Puskesmas harus dicukupkan dalam menjalankan program karena sudah diplot. Berikut wawancaranya:

"eemm kalo anggarannya itu kita dari dana BOK yaa dulu kita ada dana JKN juga tapi sekarang dana JKN tidak untuk buat seperti itu dulu kan pelatihan pelatihan tu dari JKN nah sekarang semua di iniin dari BOK untuk tahun ini.dan untuk dana BOK sendiri sekarang tidak dipergunakan untuk uang transport para kader saat penyuluhan atau ada kegiatan kegiatan lain "I1

"adaaa, dari puskesmas jadi yang mendapat pelatihan dari dinas itu programer nah nanti programmer yang melatih kader wilayah gitu kalo misalanya pelatihan kader kesehatan jiwa di puskesmas itu hanya satu wilayah satu seperti itu. "I4

"lama yaaa udah lama juga pelatihan kadernya tentang sssss apa yaa eee depresi trus nanti ada istilah apanya gitu saya lupa lagi dikasih itunya juga si sama bu yeni modulnya ada cara menanganinya seperti apaa gitu ada gitu" I5

" waktu itu pernah ikut yang dari dinas social pas itu kita 2 kali ya di nusa bangsa, dinas social kerja sama dengan puskesmas sindang barang." I6

"Kalo untuk dana itu berasal dari BOK yaaa, kalo dulu dari JKN setau saya.tapi untuk sekarang saya kurang tau karna yang mengelola semuanya bu yeni" I2

Kemudian dalam pelaksanaannya pasien BPJS tidak dikenakan biaya seperti kutipan wawancara berikut ini :

"kalo udah beberapa tahun kayaknya mah udah ngg dapet dana transport, biasanya suka ada tapi sekarang ngga ada" I3

"eeee ni ya kalo saya mah da gratis kan make apa tah nu ti pemerintah tea ... heeuh BPJS pemerintah." I9

"alhamdulah ibumah gratis pake BPJS." I8

"karna saya Pake jaminan pemerintah kali ya jadi ngga bayar Cuma kayaknya kalo ngga peke jaminan pemerintah gitumah bayar pendaftaran di depan." I12

\section{c. Sarana dan Prasarana}

Berasarkan Peraturan Menteri Kesehatan Republik Indonesia Nomor 4 Tahun 2019 Tentang Standar Teknis Pemenuhan Mutu Pelayanan Dasar Pada Standar Pelayanan Minimal Bidang Kesehatan menyebutkan bahwa sarana dan prasarana yang harus tersedia guna menunjang pelaksanaan program kesehatan jiwa sebagai berikut: 
Tabel 5. 6 Standar Teknis pemenuhan mutu pelayanan dasar pada program kesehatan jiwa

\begin{tabular}{|c|c|c|c|}
\hline No & Barang & Jumlah & Fungsi \\
\hline 1. & $\begin{array}{l}\text { Buku Pedoman } \\
\text { Diagnosis } \\
\text { Penggolongan } \\
\text { Gangguan Jiwa } \\
\text { (PDPGJ III) } \\
\text { atau buku } \\
\text { Pedoman } \\
\text { Diagnosis } \\
\text { Penggolongan } \\
\text { Gangguan Jiwa } \\
\text { terbaru (bila } \\
\text { sudah tersedia) }\end{array}$ & $\begin{array}{l}\text { Minimal } 1 \\
\text { per } \\
\text { puskesmas }\end{array}$ & $\begin{array}{l}\text { Pedoman gejala } \\
\text { klinis ODGJ } \\
\text { (Psikotik akut dan } \\
\text { Skizofrenia) untuk } \\
\text { menentukan } \\
\text { diagnosis }\end{array}$ \\
\hline 2. & $\begin{array}{l}\text { Penyediaan } \\
\text { Formulir } \\
\text { Pencatatan dan } \\
\text { Pelaporan }\end{array}$ & $\begin{array}{l}\text { Sesuai } \\
\text { kebutuhan }\end{array}$ & $\begin{array}{l}\text { Pencatatan dan } \\
\text { Pelaporan }\end{array}$ \\
\hline 3. & Media KIE & $\begin{array}{l}\text { Sesuai } \\
\text { kebutuhan }\end{array}$ & $\begin{array}{l}\text { Media Komunikasi, } \\
\text { Informasi dan } \\
\text { edukasi sebagai alat } \\
\text { penyuluhan }\end{array}$ \\
\hline
\end{tabular}

Sumber: permenkes, 2019

Sarana diperlukan untuk mendukung terlaksananya program Upaya Kesehatan Jiwa di wilayah kerja puskesmas. Sarana yang dibutuhkan sama seperti sarana untuk menangani pasien umum (tidak dibutuhkan alat khusus), berikut wawancaranya :

"sarana prasarana paling kita ada form khusus untuk pasien dan bebrapa berkas untuk deteksi dini serta ada juga media media untuk penyuluhan. Untuk ruangan juga kami telah memiliki ruang curhat khusus untuk program kesehatan jiwa serta ada juga obat obatan yang di supply dari Dinkes "I1

" obat obatan itu di supply dari dinas,untuk form untuk deteksi dini serta tersedia juga rekam medis para pasien dan alat alat untuk penunjang program penyuluhan yang rutin diadakan." I2

"untuk kader itu eeeeu dikasih form buat deteksi dini neng kalo buat pasien yang dateng ke puskesmas mah yaa ada catatan berobatnya ada rekam medisnya kan kalo tiap penyuluhan juga biasanya bu yeni bikin media sendiri gitu "I12

"kalo untuk pelayanan cukup, karna sudah ada media untuk penyuluhan yang dibuat khusus oleh bu yeni, form deteksi dini juga sudah ada, dan ruangan yang sudah memisah dari poli yang lain.." I5

Kendala mengenai sarana dan prasarana yang ada di puskesmas sindang barang salah satunya mengenai obat obatan. Di Puskesmas sudah dapat memberikan obat dengan kriteria terbatas, namun jika dengan obat tersebut tidak teratasi maka pasien dirujuk ke RSMM, Seperti pernyataan informan berikut:

" iya gini kan kalo puskesmas itu kan tidak bisa semua obat obat yang ada di puskesmas 
karna ada tingkatan levelnya kalo puskesmas ini kan hanya obat obat dasar jadi kalo tidak ada kita rujuk ke marzoeki mahdi atau ke tipe c dulu gitu." I1

"kalo obat obatan alhamdulilah ada tapi hanya suntikan aja di rujuk ke marzoeki Mahdi" I5

" eeee kalo obat tiap dua minggu sekali selalu diambil tapi selalu ada sih kalo saya mah kalo gak ada palingan di eeeee di rujuk neng." I8

" iyee ini kalo ugeng ngamuk lagi trus kaga mau minum obat lagi mah ya dirujuk ke marzoeki lagi soalnya kan di puskesmasjuga udah kaga bisa ditanganin lagi..."I10

\section{Proses}

\section{a. Penyuluhan}

Penyuluhan kesehatan jiwa adalah kegiatan pemberian informasi kesehatan kepada masyarakat tentang penanganan orang dengan gangguan jiwa, cara pendekatannya, obatobatan bagi penderita gangguan jiwa, tanda-tanda orang dengan gangguan jiwa dan sikap yang terkait. Penyuluhan kesehatan diberikan oleh pihak Puskesmas melalui petugas kesehatan yakni kegiatan mempromosikan kesehatan jiwa dan memberikan pemahaman terkait mekanisme pertahanan jiwa kepada masyarakat. Hal ini selaras dengan pernyataan dibawah:

" kita mengadakan penyuluhan itu kan sesuai dengan peraturan pemerintah ya dan kami juga melakukan penyluhan dengan inovasi salah satunya dengan mengadakan pertemuan dengan keluarga pasien dan masyarakat setempat agar mereka mengetahui gejala gangguan jiwa itu apa saja serta bagaimana cara menanganinya." I1

"untuk menghilangkan stigma di masyarakat ya karna kan untuk stigma itu yang lumayan sulit untuk dihilangkan dan cara kami agar sedikit demi sedkit ya dengan cara penyuluhan itu sendiri.serta agar masyarakat tau apa itu kesehatan jiwa,dan untuk keluarga pasien agar mengetahui cara menanganinya." I2

Adapun beberapa sdm yang terlibat dalam penyuluhan program kesehatan jiwa di puskesmas sindang barang, berikut kutipan wawancaranya:

" diantaranya bu yeni,kadang sendiri kadang kalo ada dari marzokei Mahdi banyakan dianter sama kader." I4

"yang saya sering liat mah bu yeni aja sih palingan ama kader disini tapi waktu itu pernah si sama dokter siapa gitu saya lupa dari marzoeki lumayan tuh banyakan yang ikutannya juga jadi rame dia aula teh pas kapan ya ituteh udah taun kemaren asaan mah da "I11

Untuk pelaksanaan penyuluhan itu sendiri pihak puskemsas rutin mengadakannya 3 kali dalam 1 tahun hal ini di paparkan oleh programmer program kesehatan jiwa sebagai berikut: "adaaa jadi setaun itu 3 kali itu untuk secara khusus gitu yaaa nanti kita undang psikiater khusus yang bekerja sama dengan pihak mazoeki mahdi untuk keluarga pasien maupun masyarakat gitu tapi kita juga penyuluhan ke sekolah gitu jadi penyuluhan kita itu ada kelompok sehat ada kelompok resiko ada kelompok gangguan gituu.." I1 
Hal ini selaras dengan pernyataan para kader di tiap tiap wilayah kerja puskesmas sindang barang :

"eee lumayan sering lupa si ibu berapanya mah tapi 3 kalian mah ada." I3

" taun inimah belum tapi asaan taun kemaren mah sering di kelurahan tah biasanyamah kalo gabungan yang ada dokternya mahh asaan 4 apa berapa kali ya gitu." I9

"waktu itu mah di kelurahan ada tah 2 kali yang di sini mah baru satu kali neng kalo yang dikelurahan mah gabungan gitu sama daeri mana mana gitu." I6

Terdapat kendala dalam melaksanakan kegiatan penyuluhan kesehatan salah satunya perihal dana. berikut kutipan wawancaranya:

"hambatan nya materi aja neng kan kadang puskesmas ngadain penyuluhan ya di kelurahan kan kudu naek angkot neng kita kan ngga selalu ada buat ongkos juga gitu aja sih neng." I9

"yaaa eee gimana yaaaa kan kita jauh teh buat datengnya kadang ngga ada ongkos gitu teh kan naek angkot kalo dari sini mah teh,kalo penyuluhannya di daerah sini mah saya masih suka ikut tapi ini teh kadang suka gabungan gitu teh penyuluhannya." I12

Hal ini selaras dengan pernyataan petugas puskesmas mengenai kendala saat mengadakan penyuluhan yang di alami oleh keluarga pasien :

"emm gini yaa dulu dananya JKN kalo kita mengadakan penyuluhan kepada keluarga maupun ODGJ nya kita itu selalu memberikan uang transport 50rb per orang nah sekarang peraturan baru itu dana BOK tidak boleh ada nah itu kadang kadang mereka tuh pake dana pun suka pada tidak hadir gituloh apalagi tidak pake dana apalagi wilayah kita itu cakupannya jauh-jauhkan mereka butuh untuk ongkos jg kan gitu." I1

"hambatannya ya mengenai keaktifan keluarga pasien untuk keikutsertaan dalam penyuluhan si, Jadi banyak sekali keluarga pasien atau masyarakat yang tidak mengikuti penyuluhan yang diadakan oleh kami" I2

Adapun penyuluhan yang dilakukan oleh pihak puskesmas mengenai stigma di masyarakat mengenai pasien ODGJ sebagai berikut:

"difokuskan kepada keluarga ya karna kan eee pasien itu kebanyakan minder dan keluarga itu harus memberikan semangat gitu,jadi penyuluhan itu terutama untuk keluarga dan masyarakat ya biar ngga dikucilkan gitu pasien dan keluarganya gitu." I5 "jadi gini ya untuk penyuluhan ya kita ngga hanya buat pasien atau keluarga aja tapi untuk masyarakat juga karna kan masyarakat dikita ini belum apa yaa eee belum semua menerima perbedaan lah ya intinya jadi stigma stigma di masyarakat itu masih banyak sekali nah cara satu satunya ya agar mereka terpapar pengetahuan tentang odgj ya kita selipkan mengenai stigma di masyarakat dalam setiap penyuluhan seperti itu." I1 


\section{b. Deteksi Dini}

Dinkes kota Bogor akan mengupayakan pencegahan masalah kesehatan jiwa dengan melakukan deteksi dini masalah kesehatan jiwa. Harapan dari deteksi ini ialah dapat menemukan masalah kesehatan jiwa lebih awal sehingga pengobatannya tidak terlalu berat. Kota Bogor memiliki kader kesehatan jiwa yang berperan dalam melakukan deteksi masyarakat yang memiliki masalah kesehatan jiwa. Kader mendatangi rumah masyarakat dan melakukan deteksi apakah ada anggota keluarga yang memiliki masalah kesehatan jiwa. Seperti pada kutipan wawancara berikut:

" eeee ditanya keluarganya semua, trus dia merasa dia masuknya ke resiko,sehat apa gangguan gitu, jadi ada 3 faktor kalo memang dia merasakan tidak ada keluhanya sehat kalo dia merasakan berat bebannya ke resiko dan berat lewat dari resiko yak gangguan jiwa gitu. " I6

" eeee awalnya misalnya si orang itu diam, ngaco gitu ya berhalusinasi,ngomong sendiri kaya gitu itu aja si yang saya tau.yang lebih ke ini yang berhalusinasi jadi kalo saya sih ngikutin cara bu yeni wawancaranya kaya nanya suka ada dengeran dengeran ngga? Suka ada ngomong sendiri atau apa? Seperti itu " I5

" setiap satu tahun sekali itu ada pendataan deteksi jiwa, nanti deteksi jiwa itu kita mendaptkan jumlah. Jumlah jiwa,jumlah kk,jumlah keluarga beresiko,jumlah keluarga sehat, jumlah keluarga gangguan dan jumlah kader yang terlibat dalam pendataan ini." I4 "yaaa seperti yaa kita tiap tahun selalu pendataan kalo acara rutinnya, tapi kadang ada yang bilang aja gitu kaya rt atau siapa misalnya si ini kok ngomong sendiri atau gimana gitu jadi ya kalo udah ada gejala gitu kita langsung aja survey gitu kalo emang beneran kearah kejiwaan yaudah kita infoin ke bu yeni kan jadi lebih kaya mencegah aja gitu." I7

Hal ini selaras dengan pernyataan pihak puskesmas seperti hasil wawancara dibawah:

"seperti biasa kami melakukan deteksi dini di lingkungan maupun diluar lingkungan. Dilapangan maupun di tempat kerja kami yaitu di puskesmas, untuk di puskesmas sendiri kami bekerja sama dengan seluruh pihak yang ada di puskesmas contohnya untuk di poli kia kami akan memberi format untuk perwat agar menanyakan atau melihat keadaan pasien tersebut serta kami juga memberi arahan bagaimana caramenjaga kesehatan mental dan jiwa, seperti yang kita ketahui ibu hamil riskan sekali dengan stress da nada beberapa kasus yang kami tangani juga mengenai ibu hamil. Contoh lainnya kami mengikuti program promkes yang memberikan penyuluhan kepada beberapa siswa siswi sekolahan baik tingkat smp maupum sma." I1

Selain itu pihak puskesmas juga bekerjasama dengan beberapa program di puskesmas untuk melaksanakan deteksi dini :

" eeu kita kan kerjasama sama lintas program, ada promkes ada ptm ada orang lab juga ikut biar semakin juga masyarakat juga mau gitu periksa nah terus siapa lagi orang gizi yaa terusada kader juga" I1

" hampir semuanya terlibat si untuk deteksi dini kesehatan jiwa di puskesmas sindang barang ini,seperti petugas promkes atau program program yang lainnya kader dan masyarakat di lingkungan pun ikut berperan dalam deteksi dini"I2 
"banyak ya yang terlibat itu ya dari kami sendiri yaitu kader,pihak puskesmas seperti dokter dan bu yeni ya sebagai programmer keswa." I4

" kader, eеeеeuuu rt rw sini juga kadang suka ikut mendeteksi warganya, sama pihak puskesmas." I7

Dalam program deteksi dini di puskesmas sindnag barang sejauh ini belum ada hambatan seperti kutipan hasil wawancara di bawah:

" sejauh ini yang kami alami dan rasakan belum ada hambatan untuk deteksi dini karna dalam pelaksanaan kami banyak dibantu dengan seluruh sdm puskesmas serta kader dan masyarakat setempatyang sudah mulai aktif untuk melakukan deteksi dini." I1

" eeee masih terjangkau lah ya untuk deteksi dini oleh bu yeni,dibantu juga sama pihak kader yang aktif dalam program keswa. Jadi untuk deteksi menurut saya sudah tidak ada hambatan atau halangan lagi dalam pelaksanaanya dilapangan." I2

\section{c. Rujukan}

Sistem rujukan kesehatan jiwa adalah suatu sistem penyelenggaraan pelayanan kesehatan yang melaksanakan pelimpahan wewenang dan tanggungjawab atas kasus atau masalah kesehatan jiwa yang diselenggarakan secara timbal balik, baik vertikal maupun horizontal. Rujukan vertikal dilaksanakan melalui rujukan dari satu strata sarana pelayanan kesehatan jiwa paling dasar yakni puskesmas ke strata sarana pelayanan kesehatan jiwa setingkat RSU atau RSJ. Hasil penelitian menunjukkn bahwa proses rujukan di puskesmas sudah sesuai dengan pedoman teknis yang digunakan. Berikut kutipan wawancaranya:

Berikut ini digambarkan alur rujukan rumah sakit dan rujuk balik ke puskesmas.

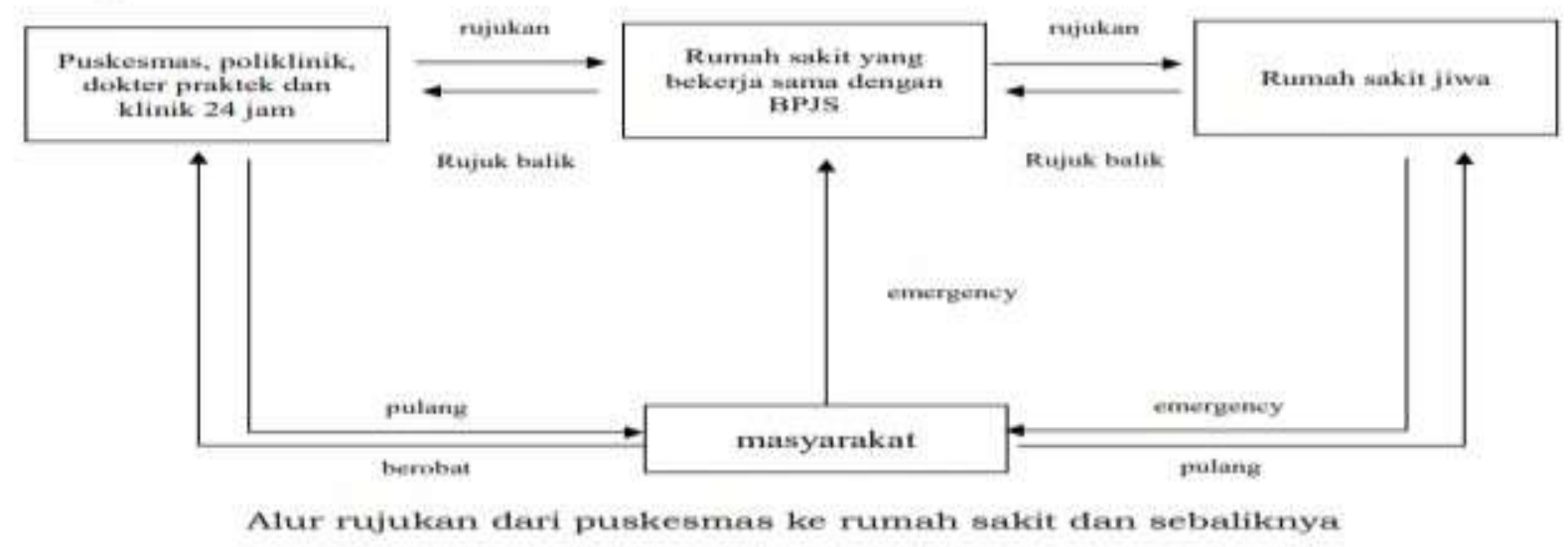

Gambar 5.2 Alur Rujukakan Kesehatan Jiwa

Peraturan Menteri Kesehatan Republik Indonesia(2017)

" kalo buat alurnya mah ya awalnya si pasien teh di bawa berobat ke puskesmas udah gitu ya dikasih obat tuh buat 14 hari si obat teh tiap hari harus diminum kalo sekiranya pasien ngga mau minum obat trus ngamuk ngamuk mah kan langsung nelepon ke bu yeni tah eeee nanti buat di marzoekinya mah itu yang daftarin bu yeni si jadi kita tinggal konfirmasi lah gitu ke bu yeni eeeee bahwa gini gini gini gitu nanti bu yeni cek dulu kelokasi kalo emang harus dirujuk ya kita mah tinggal siapin administrasinya aja kaya 
eeee bpjsnya gitu aja si yang saya taumah." I7

"kalo saya mah taunya ya kita berobat dulu ke puskesmas nanti kalo sekiranya obatnya ngga ada baru dirujuk ke marzoeki eee kalo buat rujukannya itu udah dikasih kertas resep obat aja nanti tinggal ke marzoeki gitu kaya waktu itu ada obat suntik gitu saya lupa namanya nah di puskesmas itu ngga adajadi di rujuk ke marzoeki." I11

Kendala yang sering ditemukan pada proses rujukan ini diantaranya adalah lamanya mendapat ruangan rawat inap di rs marzoeki,seperti kutipan wawancara berikut ini :

" hambatannya kemaren teh di rumah sakitnya nunggu kamar dulu sampe malem, nunggu kamar kosong dulu tuh lama banget pernah." I8

"waktu itu pernah bawa pasien orang sini dirujuk ke marzoeki eee lama banget neng nunggu di rs nya nungguin kamar kosong dulu katanya si padahal bu yeni udah kontak orang marzoeki buat minta kamar kosong eee katanya ada tapi pas udah sampe tetep aja harus nunggu dulu lama" I3

\section{Output}

\section{a. Angka Keberhasilan Program Kesehatan Jiwa}

Laporan Jiwa Tahunan di puskesmas sindang barang menyatakan ada peningkatan di setiap tahunnya,tetapi peningkatan jumlah kunjungan tersebut terjadi karena banyak pasien dari luar wilayah kerja yang berkunjung ke puskesmas sindang barang :

" banyak ya kunjungan dari luar wilayah dari dramaga tuh dari ciherang juga smpe kesini ngga tau dapet informasi dari mana tapi yaa kita tangani aja sii jadi biasanya yang kunjungan kesini bukan hanya dari wilayah kerja kita aja tapi dari luar juga sampe ada yang dari ciawi loh kesini,kita juga bingung untuk melaksanakann program dalam keswa ini gimana ke pasien yang diluar wilayah kerja karna kan kalo kejiwaan tuh bukan hanya diberi obat aja tapi juga yang lainnya gitu." I1

"banyak ya dari luar wilayah juga yang datang ke puskesmas sindang barang tapi tetep kami tangani karna kan tidak mungkin kami tolak. Tapi ya untuk kunjungan kami cukup mengalami peningkatan tetapi dalam segi deteksi dini juga kami mengalami peningkatan" I2

Berdasarkan hasil penelitian di dapatkan bahwa upaya pelaksanaan program kesehatan jiwa belum berjalan secara maksimal dimana masih ada bebrapa kendala seperti yang ada dalam kutipan wawancara berikut:

"udah bagus si ya kalo kata saya mah karna ya bu yeni udah banyak kegiatan juga untuk kesehatan jiwa ini tapi ya paling itu aja sih kurangnya di petugasnya atau dokternya aja yang belum turun langsung kelapangan selain bu yeni yaa." I4

"itu tadi ya kalo penyuluhan tempatnya kadang suka jauh jadi harus naik angkot kan 3 kali dari sini mah." I10

"eeu gini ya bagus mah bagus lah ya bu yeni juga aktif,kurangnya di eeee itu si obat aja palingann" I3 


\section{PEMBAHASAN}

1. Input

\section{a. Sumber Daya Manusia}

Berdasarkan hasil wawancara dengan 12 informan yang terdiri dari 1 programmer kesehatan jiwa,1 dokter umum,5 kader wilayah, dan 5 keluarga pasien sumber daya yang dimiliki puskesmas belum cukup karena jumlah wilayah yang cukup luas dan kurang terjangkau dengan sumber daya di puskesmas yang ada serta ada beberapa sumber daya yang belum sama sekali mengikuti pelatihan mengenai kesehatan jiwa menjadi salah satu hambatan dalam program kesehatan jiwa di puskesmas sindang barang.

Hal ini sesuai dengan penelitian Indri Yunita (2019) bahwa dalam program kesehatan jiwa terdapat 1 orang dokter umum,1 orang perawat dan kader wilayah yang telah mengikuti pelatihan khusus mengenai kesehatan jiwa. Pelatihan itu sendiri bertujuan agar tenaga yang ada memiliki kemampuan yang baik dan sebagai peningkatan pengetahuan gangguan jiwa.

Diperlukannya peningkatan sumber daya manusia di setiap unit karena kekurangan pelayanan mengakibatkan tidak terjangkaunya pasien oleh pihak puskesmas hal ini juga tertuang dalam Permenkes RI nomor 43 tahun 2016 Sumber Daya Manusia yang terlibat dalam program kesehatan jiwa di pusksemas adalah Perawat,Dokter dan Kader yang dilatih oleh nakes. Hal ini selaras dengan Depkes (2007) Pelatihan merupakan salah satu upaya untuk meningkatkan pengetahuan, sikap dan keterampilan petugas dalam rangka meningkatkan mutu dan kinerja petugas.

\section{b. Sarana dan Prasarana}

Berdasarkan hasil wawancara dengan narasumber mengatakan bahwa sarana dan prasarana yang terdapat di puskesmas sindang barang terdapat ruangan khusus untuk pasien ODGJ yang terpisah dari pasien yang lain,form khusus untuk pasien ,buku pedoman kader untuk melakukan deteksi dini, media KIE (komunikasi,informasi dan edukasi) serta selain itu terdapat juga obat untuk para pasien ODGJ. Para pasien ODGJ diberikan obat setiap 14 hari satu kali dengan cara kunjungan ke puskesmas jika pasien tidak bisa kunjungan bisa diwakilakan oleh keluarga pasien atau kader wilayah tetapi ada beberapa obat yang tidak tersedia di puskesmas maka dari itu dilakukannya rujukan ke strata sarana pelayanan kesehatan jiwa setingkat RSU atau RSJ.

Salah satu sarana prasarana yang terdapat dalam puskesmas menurut Carla.R (2011) Terdapat buku pedoman untuk setiap program di Puskesmas, termasuk untuk program kesehatan jiwa. Form laporan bulanan untuk gangguan jiwa juga disediakan. Form laporan bulanan ini membedakan gangguan jiwa menjadi psikotik, neurotic, retardasi mental, gangguan jiwa pada anak dan remaja, serta gangguan jiwa yang tidak terinci selain itu menurut Carla R (2011) juga Mengintegrasikan kesehatan jiwa di pelayanan primer seharusnya termasuk menyediakan obat-obatan yang adekuat dan dapat diandalkan. Pada beberapa kasus, obat- obatan ini tidak pernah dipakai, pada kasus yang lain obat-obatan ini kadang tidak tersedia.

Hal ini selaras dengan Peraturan Menteri Kesehatan Republik Indonesia Nomor 4 Tahun 2019 Tentang Standar Teknis Pemenuhan Mutu Pelayanan Dasar Pada Standar Pelayanan 
Minimal Bidang Kesehatan yaitu terdapat Buku Pedoman Diagnosis Penggolongan Gangguan Jiwa (PDPGJ III) atau buku Pedoman Diagnosis Penggolongan Gangguan Jiwa terbaru (bila sudah tersedia), Penyediaan Formulir Pencatatan dan Pelaporan,serta media KIE.

\section{c. Dana}

Berdasarkan hasil penelitian didapatkan informasi bahwa anggaran untuk kegiatan program kesehatan jiwa di puskesmas sindang barang berasal dari dana BOK.

BOK merupakan bantuan pemerintah pusat kepada pemerintah daerah untuk mendukung operasional puskesmas dalam rangka pencapaian program kesehatan prioritas nasional bidang kesehatan, khususnya kegiatan promotif dan preventif sebagai bagian dari upaya kesehatan masyarakat. Bantuan Operasional Kesehatan (BOK) disalurkan melalui Dinas Kesehatan Kabupaten/Kota dan dikelola Puskesmas. Penggunaan dana BOK yang telah dialokasikan di setiap Puskesmas dapat digunakan untuk pelaksanaan kegiatan dan upaya kesehatan masyarakat.

Menurut Permenkes No.3 (2019) Dana Bantuan Operasional Kesehatan merupakan salah satu sumber pendanaan untuk menunjang operasional pelayanan di Puskesmas. Hasil penelitian Jesicca Masta (2019) Dana yang diterima puskesmas untuk menjalankan program Upaya Kesehatan Jiwa berasal dari BOK (Biaya Operasional Kesehatan) dari pusat.

\section{Proses}

\section{a. Penyuluhan}

Berdasarkan hasil wawancara diketahui bahwa penyuluhan rutin diadakan dalam 1 tahun serta yang terlibat dalam penyuluhan yaitu programmer, kader wilayah, keluarga pasien, pasien serta puskesmas sindang barang sering melakukan kerjasama dengan pihak dari rumah sakit marzoeki Mahdi,selain itu penyuluhan dilakukan bukan hanya untuk pasien atau keluarga pasien saja tetapi penyuluhan juga dilakukan untuk masyarakat setempat agar menghindari atau menghapus stigma ODGJ dalam masyarakat. Terdapat kendala saat mengadakan penyuluhan,salah satunya adalah keterbatasan tempat serta dana yang menjadi penghalang dalam melaksanakan kegiatan penyuluhan tersebut.

Menurut Jesicca Masta (2019) Penyuluhan kesehatan jiwa adalah kegiatan pemberian informasi kesehatan kepada masyarakat tentang penanganan orang dengan gangguan jiwa, cara pendekatannya, obat-obatan bagi penderita gangguan jiwa, tanda-tanda orang dengan gangguan jiwa dan sikap yang terkait. Sedangkan menurut Uswatun Hasanah (2019) Penyuluhan kesehatan adalah proses untuk meningkatkan kemampuan masyarakat dalam memelihara dan meningkatkan kesehatan.

Dikarenakan ada beberapa kendala saat pelaksanaan penyuluhan kesehatan jiwa di wilayah sindang barang terutama keterbatasan dana dan tempat,maka dari itu baiknya pihak puskesmas mengadakan penyuluhan di setiap kelurahan agar lebih terjangkau oleh masyarakat setempat. Hal ini selaras dengan Undang-Undang Republik Indonesia Nomor 18 Tahun 2014 Tentang Kesehatan Jiwa bahwa Upaya promotif di lingkungan fasilitas pelayanan kesehatan sebagaimana dimaksud pada ayat (1) huruf e dilaksanakan dalam bentuk komunikasi, informasi, dan edukasi mengenai Kesehatan Jiwa dengan sasaran kelompok pasien, kelompok keluarga, atau masyarakat di sekitar fasilitas pelayanan kesehatan. 


\section{b. Deteksi Dini}

Berdasarkan informasi yang didapatkan dari hasil penelitian bahwa di setiap wilayah kader sudah mendapatkan pelatihan mengenai deteksi dini di wilayah masing-masing. Selain deteksi dini di luar gedung, puskesmas melakukan deteksi di dalam gedung dengan cara bekerjasama dengan lintas program yang ada di puskemas sindang barang.

Menurut Indri (2019) Upaya pencegahan masalah kesehatan jiwa dengan melakukan deteksi dini kesehatan jiwa, Harapan dari deteksi ini ialah dapat menemukan masalah kesehatan jiwa lebih awal sehingga pengobatannya tidak terlalu berat. Serta menurut penelitian jesicca (2018) deteksi dini adalah kegiatan menggolongkan pasien dengan gangguan jiwa berdasarkan keluhan psikis yang frekuensinya berkelanjutan (pusing, sakit perut, tidak bisa tidur) walaupun pada saat dilakukan pemeriksaan fisik pasien dinyatakan sehat

Dalam pelaksanaan deteksi dini di puskesmas sindang barang sudah cukup maksimal karena deteksi dini dilakukan oleh semua sektor wilayah yang berada di lingkungan puskesmas sindang barang. Hal ini selaras dengan Menurut Keputusan Mentri Kesehatan Republik Indonesia tahun 2009 Tentang Pedoman Pelayanan Kesehtaan Jiwa Komunitas yaitu Komponen di fasilitas pelayanan kesehatan tingkat primer dapat diselenggarakan pelayanan salah satunya adalah deteksi dini.

\section{c. Rujukan}

Menurut Keputusan Menteri Kesehatan Republik Indonesia Nomor: 406/MENKES/SK/VI/2009 Sistem rujukan adalah tatanan pelayanan yang berjenjang dan saling berinteraksi antara unit-unit pelayanan dari berbagai tingkatan (primer s/d tertier) untuk mencapai tujuan pelayanan. Melalui sistern rujukan diharapkan akses pelayanan dipermudah, penumpukan pelayann di cegah dan pelayanan berjalan secara optimal.

Hal tersebut selaras dengan penelitian Jessica masta (2019) Mengatakan bahwa pengelolaan rujukan balik kasus gangguan jiwa merupakan pengelolaan tatanan pelayanan yang dilakukan secara berjenjang antar unit pelayanan dari berbagai tingkatan.

Berdasarkan hasil wawancara dengan petugas Puskesmas, diketahui bahwa rujukan di puskesmas sindang barang tidak cukup baik dilaksanakan karena ada beberapa hambatan seperti tidak ada surat izin dari pihak keluarga untuk melaksanakan rujukan ke rsj karna dalam Permenkes No.54 (2017) Bahwa salah satu syarat atau ketentuan untuk melakukan rujukan adalah surat izin dari pihak keluarga. Sedangkan kader wilayah mengatakan hambatan yang terdapat saat melaksanakan rujukan yaitu kurangnya ketanggapan dari pihak RS untuk pasien serta miskomunkasi antara pihak puskesmas dengan pihak rumah sakit.

Rujukan ODGJ dapat dilakukan jika pasien Tetap agresif dan tidak kooperatif meskipun telah dilakukan penatalaksanaan psikofarmaka dan mendapat penatalaksanaan gejala dengan terapi non farmakologis di pelayanan kesehatan tingkat pertama, Ditemukan kondisi kegawat daruratan psikiatri atau terdapat penyakit penyerta maka dilakukan rujukan kesarana pelayanan rujukan dan tidak tersedianya obat tertentu yang dibutuhkan oleh pasien di puskesmas. 


\section{Output}

\section{a. Angka Keberhasilan Program Kesehatan Jiwa}

Dari hasil penelitian didapatkan pula informasi bahwa banyak pasien dari luar wilayah kerja yang mengunjungi poli kejiwaan di puskesmas sindang barang. Angka cakupan deteksi dini gangguan kesehatan jiwa di wilayah kerja Puskesmas sindang barang dan angka cakupan penanganan pasien terdeteksi gangguan keesehatan jiwa sudah mencapai target yang ada pada tahun 2018, untuk data pada tahun 2019 puskesmas belum mengolahnya. Untuk jumlah kunjungan tersediri pada tahun 2017-2018 mengalami peningkatan dan untuk tahun 2018-2019 masih dalam pengolahan.

\section{DAFTAR PUSTAKA}

Ayuningtyas, Dumilah, Misnaniarti Misnaniarti, Siti Khodijah Parinduri, Fitria Aryani Susanti, Ni Nyoman Dwi Sutrisnawati, and Sayyidatul Munawaroh. "Local Initiatives In Preventing Coronavirus Based On Health Policy Perceptive." Journal of Indonesian Health Policy and Administration 5, no. 2 (2020).

Ayuningtyas,D., Parinduri,S. K.dan Susanti, F. A. 2018. Integritas Kepemimpinan Antikorupsi di Sektor Kesehatan.Jurnal Integritas 4(1): 5.

Asnifatima A, Parinduri SK, Aligori A. (2020). Risiko dan Karakteristik Penderita Toksoplasmosis berdasarkan Demografi, Keberadaan Hewan Peliharaan, Hygiene dan Sanitasi. Heart, Jurnal Kesehatan Masyarakat,8(X), 41-49.

Arsyati Asri Masitha, 2019, pengaruh penyuluhan media audiovisual dalam pengetahuan pencegahan stunting pada ibu hamil di desa cibatok 2 cibungbulang pengaruh penyuluhan media audiovisual dalam Pengetahuan pencegahan stunting pada ibu hamil di desa, PROMOTOR Jurnal Mahasiswa Kesehatan Masyarakat, Vol. 2 No. 3, Juni 2019

Asri Masitha Arsyati, Vindi Krisna Chandra, 2020. Assement Kesiapan Kader Posyandu dalam Pelatihan Penggunaan Media Online. HEARTY Jurnal Kesehatan Masyarakat Vol.8 No.1, 2020 Agustus-February, hlm. 27-32 ISSN. 2338-7475 E-ISSN. 2620-7869

Arsyati, Asri Masitha ; Hadi Pratomo, Irawati Ismail, Sabarinah Prasetyo, Rita Damayanti. (2017). Pengembangan Media Cetak Pendidikan Pencegahan Kekerasan Seksual Balita Di Kota Bogor. Hearty Jurnal Kesmas, Vol.5 no.1 tahun 2017. Penerbit Universitas Ibn Kahldun Bogor. http://ejournal.uika-bogor.ac.id/index.php/Hearty/article/view/1052

Arsyati, A.M., \& Rahayu, Y.T. (2019). Budaya pemberian makanan pendamping ASI (MP-ASI) pada bayi usia kurang dari bulan di desa Leuwibatu Rumpin. Jurnal kesehatan masyarakat, 7(1), 9-17

A Nasution, A Maulana, D Kurniawan. (2019). BERSAMA MEMAJUKAN DESA. Abdi Dosen: Jurnal Pengabdian Pada Masyarakat 3 (2), 99-104

B. Rizki, D. Fitriana, R. Hidana, S.K. Parinduri, Analisis Penerapan Sistem Informasi Manajemen Puskesmas (Simpus) dengan Model Human Organization Technology (HOT)-Fit di Puskesmas Tanah Sareal Kota Bogor Tahun 2019 Pendahuluan Metode, PROMOTOR: Jurnal Mahasiswa Kesehatan Masyarakat 3(1) (2020) 18-27.

Fitrianingtyas, Pertiwi, dan Rachmania, W. Faktor-Faktor yang Berhubungan dengan Kejadian Kurang Energi Kronis (KEK) pada Ibu Hamil di Puskesmas Warung Jambu Kota Bogor. HEARTY Jurnal Kesehatan Masyarakat. 2018;6(2):1-8. 
Hanissa, J., Nasution, A., \& Arsyati, A. M. 2017. "Gambaran Perilaku Personal Hygiene Menstruasi Remaja Putri Yang Mengikuti Pelatihan Dan Pembinaan Pkpr Di Smp Pgri 13 Wilayah Kerja Puskesmas Sindang Barang Kota Bogor Tahun 2017". Hearty Jurnal Kesehatan Masyarakat, 5(2).

Indri Yunita Suryaputri, N. H. (2019). Gambaran Upaya Pelayanan Kesehatan Jiwa Berbasis Komunitas di Kota Bogor . Buletin Penelitian Kesehatan, 21.

Jessica Masta Hothasian, C. S. (2019). Evaluasi Pelaksanaan Program Upaya Kesehatan Jiwa Di Puskesmas Bandarharjo Kota Semarang.

Marchira, C. R. (2011). Integrasi Kesehatan Jiwa Pada Pelayanan Primer Di Indonesia:Jurnal Manajemen Pelayanan Kesehatan, 122-124.

Mariyamah ,S., Asri M. A., Ade Saputra N. (2020). Respon Mahasiswa Terhadap Pictorial Health Warning di Fakultas Teknik Universitas Ibn Khaldun Tahun 2020. Jurnal Mahasiswa Kesehatan Masyarakat. Vol. 3 No. 5

P. S. Akbar, S. K. Parinduri, and R. Hidana, "Gambaran Pelaksanaan Surveilans Epidemiologi Di Rumah Sakit Umum Daerah Leuwiliang Kabupaten Bogor Tahun 2018,” PROMOTOR, vol. 2, no. 5, pp. 410-421, 2019.

Pratiwi, A. M. (2015). Model Pelayanan Kesehatan Berbasis Partisipasi Masyarakat Untuk Meningkatkan Pelayanan Kesehatan Jiwa Pada Masyarakat Setempat. Muhammadiyah University of Surakarta, 56.

Pertiwi, F. D., Hariansyah, M., \& Prasetya, E. P. (2019). FAKTOR RISIKO STUNTING PADA BALITA DIKELURAHAN MULYAHARJA TAHUN 2019. PROMOTOR, 2(5). https://doi.org/10.32832/pro.v2i5.2531

Pertiwi, F. D., Rahman, R. M., \& Lestari, D. W. (2018). Pemberdayaan masyarakat melalui bidang literasi di Desawaru Jaya. Jurnal ABDI DOSEN: Jurnal Pengabdian Pada Masyarakat, 2(2), 129-137. https://doi.org/10.32832/abdidos.v2i2.170

Rinata, F., Arsyati, A. M., \& Maryati, H. (2019). Gambaran Implementasi Program Rujuk Balik (Prb) Bpjs Kesehatan Di Puskesmas Wilayah Kerja Kecamatan Tanah Sareal Kota Bogor .... Promotor.

Rochmawati, D., \& Arsyati, A. M. J. P. (2019). Gambaran Keterpaparan Media Berkonten Pornografi Pada Anak-Anak Peserta Didik Kelas 4, 5 Dan 6 Di Sdn Kayu Manis 2 Kota Bogor. 2(5), 351-360.Ngadiran, Antonius (2010). Studi Fenomenologi Pengalaman Keluarga Tentang Beban dan Sumber Dukungan Keluarga Dalam Merawat Klien Dengan Halusinasi. Tesis. Depok, FIK-UI. 